\title{
Hernández Catá, Cuentista
}

POR aquella época, hace ya muchos años, una incurable apatía me vedaba todo propósito de creación literaria. $\mathrm{Y}$ una tarde que nunca olvidaré, Hernández Catá, generosamente ansioso de ganarme otra vez para el arte, hubo de decirme:

- Serpa, usted es un hombre que frustra su destino.

Había en esta frase, tanto como en las admoniciones que después formuló, tal acento fraternal, tal fermento de noble melancolía, que, turbado de súbito, yo rompí a reír, para no confesar que estaba demasiado conmovido.

Luego, durante el discurrir de los años, han fulgurado en mi memoria, profusas veces, aquellas palabras. $Y$ con insistente admiración me han hecho meditar que la vida de quien las pronunció era, cabalmente, la antitesis de la mía. $\mathrm{Y}$ así se aelvierte diáfana, categóricamente expresado en la significación de su ex-libris, que no se resigna a simple grabado decorativo, ni a mero signo de posesión, sino que obtiene vigencia de símbolo y pronóstico. La intuición del artista que lo creó devino gracia profética. Porque ese desnudo torso de Sagitario, con sus pectorales vigorosos, sus brazos metalizados por la tensión del esfuerzo y su perfil impávido, trasunta una vida heroica. Y esa flecha que apunta contra el cielo, ávida de una Diana imposible, traduce una vocación determinada a cumplir con pasión inmutable su destino de gloria.

Tal destino alborea desde temprano en Hernández Catá. Y no cerrada aún la órbita de su adolescencia, cuando apenas ha dejado atrás la jubilosa irresponsabilidad de la infancia, se siente llamado a padecer largamente las agonías del arte. Responde, como quien acepta gozoso un sacrificio, a tal llamado. $Y$ con sagaz instinto acierta, desde el principio, a escoger el rumbo exacto de su vocación lite- 
raria. $\mathrm{Ni}$ dudas ni vacilaciones enturbian el claro instante de la elección consagratoria. $\mathrm{Y}$ antes de haber dado los primeros pasos, ya tiene conciencia de la totalidad del camino que habrá de recorrer. Abarca de una mirada la inmensidad de la perspectiva. $\mathrm{Y}$ discierne con segura percepción, no las alas ni las garras de su facultad creadora, pero sí el espacio y la materia en que habrá de arriesgar la fuerza de estas garras, la resistencia de aquellas alas. Y opta, entre los distintos géneros literarios, por el cuento.

No es ahora la oportunidad de plantear un problema de categorías entre los géneros literarios. $\mathrm{Y}$ menos la de pretender dilucidarlo. Pero vale la pena subrayar, sin embargo, que acaso ha sido el cuento, entre todos, el que más antagónicos criterios ha suscitado. "Género subalterno, de calidad inferior", to ha reputado más de un crítico. Y una voz ilustre, en cambio, ha dicho: "El cuento representa en la prosa lo que el soneto en la poesía." $\mathrm{Y}$ si damos por válido tal veredicto, será preciso reconocer que no resulta empresa escuálida, ciertamente, llegar a maestro del relato breve, como tampoco resulta fácil ser sonetista impecable. Pero la dificultad no equivale a imposibilidad. $Y$ catorce versos bastan a Heredia para resumir la historia de Antonio y Cleopatra; compendia en otro soneto la hazaña de los conquistadores de América. ¿Qué mucho, por lo tanto, exigir, análogamente, que un escritor ofrezca en las angostas dimensiones de un cuento su sentido de la vida, la concreción de una filosofía, el horror de una tragedia o la trayectoria de una existencia humana? No es excesiva, en efecto, tal exigencia, después de la ejemplaridad de Edgar Poe, Bret Harte, Maupassant, Villiers de 1'Isle Adam, Rudyard Kipling, Somerset Maugham, Máximo Gorki, Andreiev. Pero precisa, para rendir una tarea así, que posea el escritor facultades egregias, que van desde un insobornable espíritu de síntesis hasta un magistral dominio de la forma. Porque en el cuento, dicho sea con palabras del propio Hernández Catá, "la pluma ha de ser más certera que en las narraciones profusas, y la sobriedad, calidad de grandes, está ya impuesta, al menos en ciertos aspectos, por el imperativo de no llenar con disquisiciones o redundancias baldías el espacio que ha de faltar para lo sustantivo. La euritmia de este linaje de obras exige gusto arquitectónico depurado, pues el lector abarca, con mayor comodidad que en las extensas, la curva generatriz, y percibe las fealdades del trazo con menor esfuerzo". 
$Y$ estas palabras no han sido dictadas en función de dómine, ni para espejo y aleccionamiento de otros, sino como pautas inflexibles de la propia labor. Porque Hernández Catá, artista auténtico, aún más que por la calidad insuperable de su obra por su concepto del arte, sabe que el arte es pasión, y es misterio, y es servidumbre, $\mathrm{y}$ es heroísmo, y es vicio y es tortura: más que regalo de Dios, dádiva del demonio. Pero le ha sido dable entender, parejamente, que el arte es grandeza, tal vez la suma grandeza, acariciada en ocasiones por el sueño ambicioso del artista, pero siempre distante, infinitamente distante de la obra realizada. Y la evidencia de esta desnuda verdad lo excita a una depuración constante y a una sempiterna superación, porque le inspira, acaso más que una esperanza de gloria, el empeño de hacerse digno del arte.

La firme certidumbre de su valer despoja al artista de jactancia; la comprensión de su sino le veda poses de pedante. Y Hernández Catá posee la conciencia de este sino, tanto como aquella certidumbre. $\mathrm{Y}$ una y otra, de consuno, armónicamente, al par que lo invisten de dignidad, aportan a su espíritu la confianza en sí mismo. Acaso alguna vez podrá parecer tranquilamente orgulloso, que es en ocasiones un modo de ser digno; pero jamás incurre en la chabacanería de ser fatuo. No alienta envidias ante los méritos ajenos, ni rebaja los éxitos de nadie. Hace de la probidad intelectual un hermoso pendón. $Y$ queda en reverso del tahur literario, que, como hace con los naipes el del garito, escamotea frases o pensamientos para mentir pretensa originalidad. Hernández Catá no se engaña, ni se desvela por engañar a otros. Sabe que todo artista se encuentra inmerso, irremisiblemente, en las torrenciales aguas oscuras o en la transparente linfa de una tradición. Porque el escritor no adviene al mundo por generación espontánea, desligado del tiempo y del espacio, sino influído por la acción de una cultura, los cánones de una estética, el estilo del tiempo en que le ha tocado vivir y hasta por el aire que respira. Tales tópicos aparecen explícitos a Hernández Catá desde el comienzo. $\mathrm{Y}$ pues que desentraña hasta la medula su cabal sentido, no aspira a inventar una religión: se consagra sacerdote de un culto que ya existe. Con lúcida perspicacia advierte que no es precaria gloria, ni a.ventura sin martirio, destacar en el enorme fresco de una tradición el matiz de la individualidad propia. $Y$ pues que resplandece ante sus ojos, ya forjado, un recipiente de metal sólido y rico, se entrega 
con ardor fanático, no sólo a darle perfección y a pulir su belleza, sino, simultáneamente, a rebosarlo de su propia sustancia.

Nadie, salvo tal vez algún necio, reprocha a Rudyard Kipling que, para dar existencia a su maravillosa jungla literaria, seleccionase como simientes Bocetos californianos, de Bret Harte. Nadie tampoco ha de encontrar demérito en que, para ensayar sus primeros pasos, Hernández Catá escogiese, como guía y mentor, a Guy de Maupassant, sobre todo cuando tal elección responde, más que a superficiales gustos transitorios, a intimas razones de paridad espiritual.

No en los temas, pero sí en el modo de encarar el oficio, se columbra la sombra insigne de Maupassant en Cuentos pasionales, primer libro de Hernández Catá, en el que, como santo y seña de una personalidad poderosa, están patentes ya, tanto como las debilidades, las altas virtudes de su autor. Desde la publicación de dicho volumen, Hernández Catá habrá de ser con inalterable constancia idéntico a sí mismo. La factura podrá ser depurada hasta lograrla impecable; la técnica podrá ser más estricta; más sobrio, más acabado el estilo; pero siempre habrá entre todos sus libros, desde el inicial hasta el postrero, un sello personal que los hermana. $Y$ esto, porque Hernández Catá, leal minero de sí mismo, trabaja su cantera intelectual, no perezosamente en la superficie, sino, con heroica unción, hacia las entrañas.

Cuanto en la obra posterior de Hernández Catá ha de tener esencia de perennidad, apunta en germen, cuando no surge a plena luz, ya con formas definidas, en Cuentos pasionales, que si nada arguye, en realidad, para el lustre de su nombre, constituye, en cambio, un documento irrecusable para trazar la radiante parábola de su vida literaria. Sus preferencias temáticas, la pasión inquebrantable y férvida que siente por la forma, su don de observación, la delectación con que ha de describir los episodios patéticos, su visión dramám tica de las cosas, el ímpetu dionisíaco de una imaginación perpetuamente joven, que en ocasiones lo ha de obligar a milagros de equilibrio para eludir el melodrama; su ausencia de sonrisas y su matemático sentido de la proporción justa: todo lo que, en síntesis, ha de ser característico del gran escritor futuro, vive y alienta en este libro como el hombre en el feto. Los años que vendrán no han de servir sino para que, a fuerza de estudios persistentes y abnegados esfuerzos, vaya purificando cada vez más sus aptitudes innatas, que 
logran su esplendor más puro y su eficacia máxima en Los siete pecados, Piedras preciosas y Manicomio, marmóreos pedestales de su gloria.

Desde Los siete pecados, la obra de Hernández Catá presenta una fisonomia peculiar, no sólita en la literatura castellana. Ha llegado el escritor al cenit de stı destino. Sus facultades congénitas, alquitaradas por el estudio, la observación y la experiencia, lo han puesto en disposición de penetrar y comprender el misterio de la vida y de las almas. Todos los secretos del oficio le han sido ya revelados: nadie osaría regatear la plenitud de su victoria en la gesta de la forma. $Y$, no obstante, perdura intacto, incólume, como la flama de una lámpara votiva, el encendido fervor de su juventud primera. Mantiene vívido y alerta, cada día menos sobornable, su anhelo de perfección absoluta. X cuando desenvuelve un tema lo exprime cial un fruto, para brindarlo quintaesenciado en la brevedad de un cuento, que, como "El testigo", "La culpable", "La perla", "Los chinos" y "La galleguita", recaba jerarquía de obra maestra.

Pero lo que otorga fisonomía peculiar a la obra de Hernández Catá, no es, empero, la perfección formal de sus cuentos, sino el sentido humano y el afán de tniversalidad que los anima. Toda su pasión creadora, afinada hasta la hiperestesia, ha circunscrito al hombre como una frontera mágica. $Y$ nada externo tiene la atracción necesaria para captar su atención. El ambiente circundante no lo invita sino a una somera pincelada. $Y$ nada le dice el paisaje, ni siquiera como escenario de la conducta del hombre. No existe para él sino el ser humano. no tanto por ser humano como por morada de conflictos espirituales. Tanto es así, que a veces no es menester el pretexto de una peripecia para que suelte el azor de su análisis psicológico; basta un gesto, un ademán imperceptible, una palabra o una sonrisa, para que, con extraordinario virtuosismo, se complazca en desmontar el complejo mecanismo del alma humana. ; Y qué intrépida decisión para abismarse en esta labor de cíclope, realizada, al par que con paciencia de gusano, con la sombría práctica de un cura-confesor! Impasible y tenaz, se desliza entre viscosas tinieblas para sacar a la luz secretos y pecados, remordimientos y crímenes. $\mathrm{Y}$ con frío denuedo bucea en el alma de sus personajes, hasta recalar en zonas abisales, donde, agazapados como bestias inmundas, están los malos deseos, las pasiones abortadas, las tentaciones reprimidas, los resentimientos inconfesables. Nada lo arredra, nada to de- 
tiene: su puño es firme, buido y cruel su escalpelo: profundiza su análisis como un metálico bisturí de cirujano. Sentimientos primarios, que a otros no arrancarían sino un párrafo seco, una imagen acaso, tal vez una metáfora, provocan en Hernández Catá dramáticas orgías de psicoanálisis. Tal, por ejemplo, el miedo, viviseccionado una vez, y otra, y otra vez en narraciones que crispan los nervios. $O$ el impulso sexual. $O$ el odio, manifestado en formas disímiles, nacido de causas diferentes y hasta aposentado en el corazón de una madre. Nada es demasiado oscuro para la antorcha de Hernández Catá ; nada lo asusta, nada es bastante tenebroso para hacerlo vacilar. Seres que chapotean, míseros y patéticos, en los pantanos de la patología; almas sórdidas, que parecen amasadas con fango y pus; cerebros perturbados y conflictos siniestros estimulan su curiosidad implacable, exaltan su fantasía, lo fascinan como filtros maléficos, y le deparan la oportunidad de esculpir esa noche de pesadillas que se llama Manicomio o la amarga y angustiada desolación de El ángel de Sodoma.

Hernández Catá, sin embargo, no acierta a dar íntegra la atmósfera que demanda la intensidad de sus cuentos trágicos. Disfruta la grandeza, pero, parejamente, sufre la miseria de una prosa magnífica, impecable, que ha perdido en fưerza dramática y en capacidad para la emoción desgarrada lo que ha ganado en belleza arquitectural, en armonía y en limpieza. Prosa grávida y viva, sensual y jugosa, cálida. Prosa de carnal opulencia, que a ratos produce la impresión de que puede ser palpada, acariciada con las manos. Prosa de noble estirpe, ni prolija ni avara, situada en el justo medio, en difícil alarde de equilibrio. Prosa sin elocuencia de discurso ni música de verso, porque le basta con su adecuada euritmia de escultura. $\mathrm{Y}$ en esta prosa de aspecto fácil, siempre diáfana, encantadora de claridad, i cuántas resistencias vencidas, cuánta fatiga superada, cuánto fervor insomne, qué aprendizaje sin término, para ofrecer el milagro de que la obra terca, devota, agoniosamente elaborada, parezca de repentina improvisación! Y éste acaso sea, en definitiva, el más precioso y duradero triunfo de Hernández Catá. 